\title{
8
}
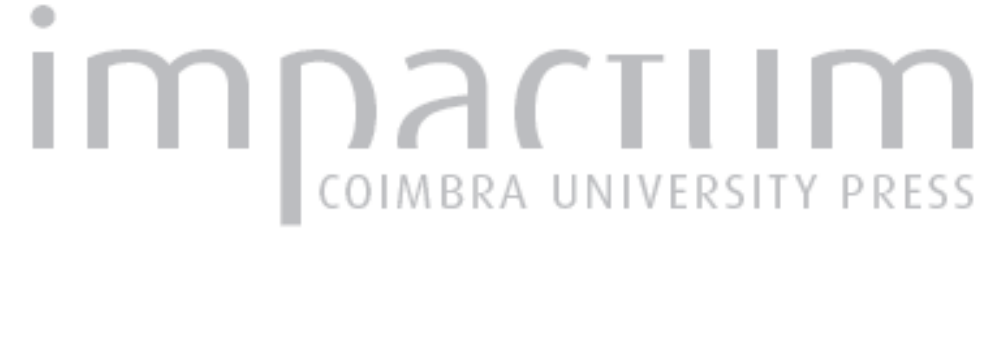

\section{Metro ligeiro de superfície na baixa de Coimbra}
Autor(es):
Byrne, Gonçalo; Bandeirinha, José António; Grande, Nuno; Lobo, Rui; Rabaça, Armando

Publicado por: Editorial do Departamento de Arquitectura

URL persistente:

URI:http://hdl.handle.net/10316.2/37495

DOI:

DOI:http://dx.doi.org/10.14195/0874-6168_6.7-1_3

Accessed : $\quad$ 26-Apr-2023 12:25:57

A navegação consulta e descarregamento dos títulos inseridos nas Bibliotecas Digitais UC Digitalis, UC Pombalina e UC Impactum, pressupõem a aceitação plena e sem reservas dos Termos e Condições de Uso destas Bibliotecas Digitais, disponíveis em https://digitalis.uc.pt/pt-pt/termos.

Conforme exposto nos referidos Termos e Condições de Uso, o descarregamento de títulos de acesso restrito requer uma licença válida de autorização devendo o utilizador aceder ao(s) documento(s) a partir de um endereço de IP da instituição detentora da supramencionada licença.

Ao utilizador é apenas permitido o descarregamento para uso pessoal, pelo que o emprego do(s) título(s) descarregado(s) para outro fim, designadamente comercial, carece de autorização do respetivo autor ou editor da obra.

Na medida em que todas as obras da UC Digitalis se encontram protegidas pelo Código do Direito de Autor e Direitos Conexos e demais legislação aplicável, toda a cópia, parcial ou total, deste documento, nos casos em que é legalmente admitida, deverá conter ou fazer-se acompanhar por este aviso.

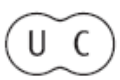




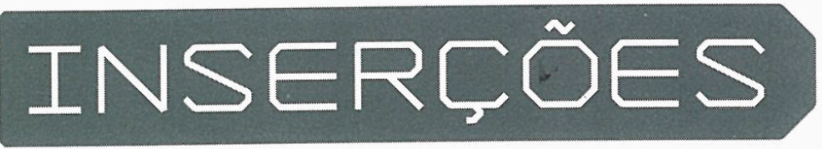

\title{
SEMINÁRIO INTERNACIONAL DE DESENHO URBANO
}

\author{
PT António Belém Lima \\ PT José Gigante \\ ISR Peter Keinan \\ ES Eduard Bru \\ PT Manuel Graça Dias + Egas José Vieira
}
BR MMBB
PT Eduardo Souto Moura
ES Emilio Tuñón + Luis Mansilla
PT Alexandre Alves Costa + Sergio Fernandez
PT Manuel Mateus + Francisco Mateus

\section{(COIMBRA COMO TERRITÓRIO)}

Walter Rossa

(PROJECTOS URBANOS EM COIMBRA )

José António Bandeirinha

(METRO LIGEIRO DE SUPERFICIE)

Gonçalo Byrne, José António Bandeirinha, Nuno Grande, Rui Lobo, Armando Rabaça

( SOBRE UM ELÉCTRICO RÁPIDO )

Paulo Bebiano Correia 


\section{METRO LIGEIRO DE SUPERFICIE NA BAIXA DE COIMBRA}

Gonçalo Byrne

José Antônio Bandeirinha

Nuno Grande

Rui Lobo

Armando Rabaça

Centro de Estudos de Arquitectura da FCTUC

\section{ATRAVESSAMENTOS URBANOS: SACRIFICIOS OU OPORTUNIDADES?}

\section{Antecedentes Urbanísticos}

0 atravessamento da Baixinha de Coimbra pelo novo Metro Ligeiro põe à cidade e aos seus cidadãos uma questão antiga no contexto da Urbanística europeia, e que ganhou especial ênfase a partir da Revolução Industrial: a do esventramento urbano.

Na verdade, a industrialização e a consequente transformação dos sistemas produtivos e dos meios de transporte, em pleno século $\mathrm{XIX}$, obrigaram as cidades a criar novas formas de organização logística muitas vezes incompatíveis com a manutenção dos tecidos urbanos herdados de séculos anteriores. 0 traçado de novos eixos rodoviários, acompanhados por outros tantos canais de transporte ferroviário, obrigaram ao sacrifício de grandes extensões de cidade, abrindo frentes de construção no interior de quarteirões preexistentes. Estes esventramentos causaram naturalmente ondas de choque e desorientação nos habitantes, mas depressa possibilitaram novas formas de agregação social e económica que mudaram por completo a condição civilizacional das cidades europeias; ou seja, apesar da imposição muitas vezes despótica desta mudança física, a cidade e os seus cidadãos conseguiram fazer desse sacrificio uma oportunidade.

O caminho-de-ferro, por exemplo, construiu a cidade vitoriana, mudando as paisagens de Londres e de outras cidades britånicas industrializadas (Manchester, Liverpool, Glasgow), então preenchidas por um novo património edificado - gares, viadutos e armazéns em pleno tecido urbano.

$\mathrm{Na}$ Paris Haussmaniana escavaram-se, em oito meses, $300.000 \mathrm{~m} 3$ de solo urbano, tornando possível, aos geometras e engenheiros des Ponts et Chaussés, abrir longos boulevards, mas também jardins públicos e passagens desniveladas, e sobretudo galerias técnicas subterrâneas para infraestruturação dos novos prédios burgueses. A uma escala ainda mais cirúrgica, o traçado do Metropolitano - então o novo transporte cosmopolita da cidade europeia - obrigou ao corte e realinhamento de ruas para construção dos "esqueletos de ferro" de túneis e estações, posteriormente baixados até às "entranhas" da cidade.

Por razões de higiene, mobilidade ou segurança, a cidade oitocentista ganhou um nível infra-urbano que permitia o seu complexo funcionamento à superfície. Por outro lado, os fluxos abertos pelos esventramentos possibilitaram a criação de novas redes de transporte, ligando vários estratos urbanos fisicamente separados. Como consequência, as cidades europeias fim-de-século tornaram-se em museus abertos de equipamento de tracção - só em Paris existiam então 12 companhias de tramway (a vapor ou ar comprimido) a operar em mais de 100 linhas urbanas.

A "corrente sanguínea" do transporte e da troca, fez da cidade industrial um espaço de irresistível magnetismo económico e de ampla mobilidade social. Desse ponto de vista, as avenidas boulevard, assim como as passagens internas de quarteirão - passages, galeries ou arcades - tornaram-se nos escaparates mais apetecíveis para a fixação do comércio a retalho, dos cafés e esplanadas, das instituições públicas, do lazer e do entretimento. Ainda em Paris, e através de acções higienistas, redimensionaram-se os longos pátios de oficinas e habitação operária - os Faubourgs - possibilitando condições de abertura e ventilação no interior dos quarteirões mais insalubres.

As diversas tipologias descritas documentam a diversidade de soluções de esventramento encontradas na reestruturação urbana de Oitocentos - desde o mais recôndito quarteirão (à escala do bairro) ao mais extenso e denso tecido urbano (à escala metropolitana) - criando, em cada uma delas, novas fronteiras de relação entre os domínios público e privado.

Estas "cidades abertas dentro da cidade" promoveram a conexão física dos tecidos medievais ou renascentistas com o tecido moderno, dando, tantas vezes, novos sentidos urbanos a fragmentos interrompidos pelas contrariedades da História. 


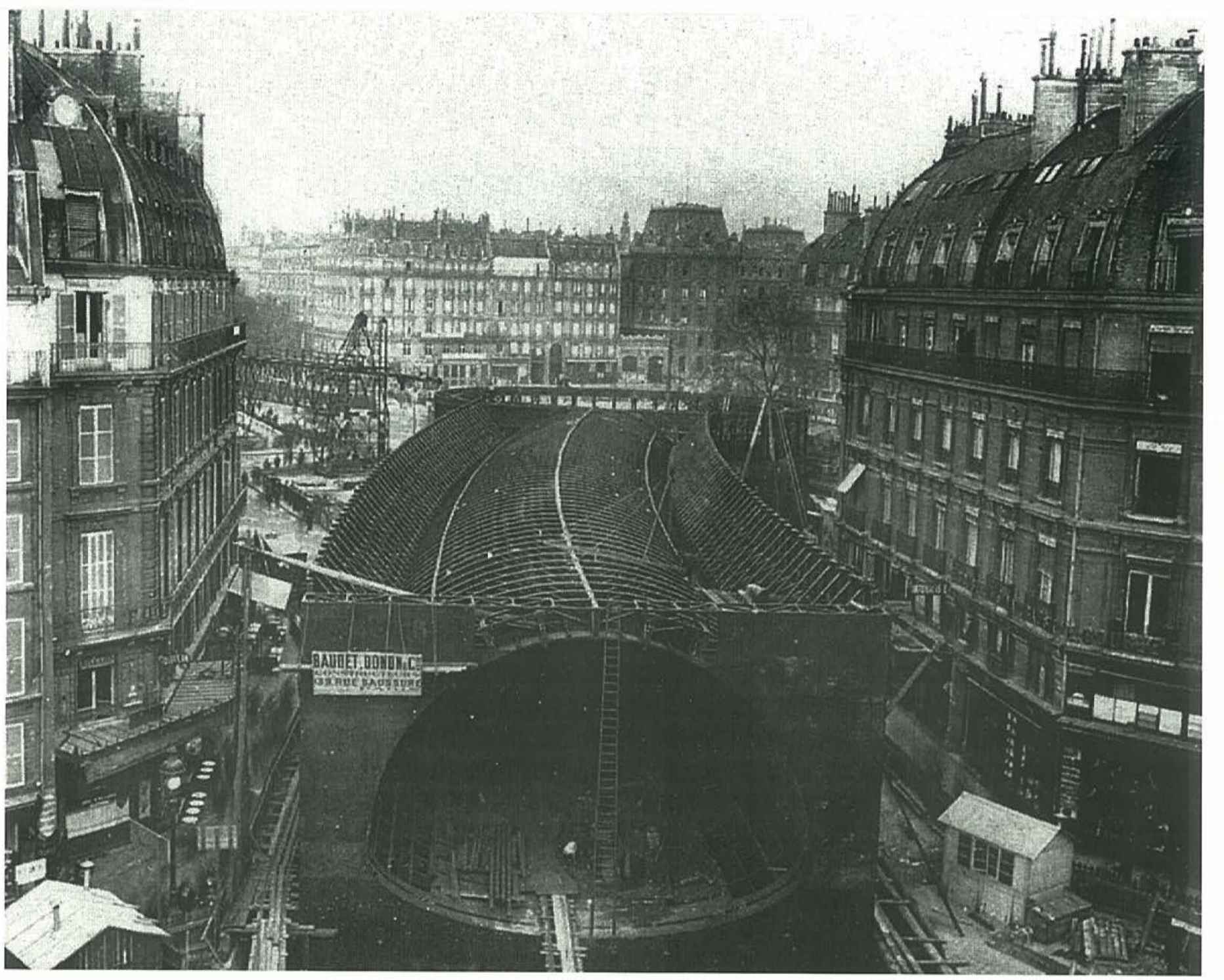

\section{Contexto Português}

A história recente da cidade portuguesa partilha as mesmas tendências das restantes europeias, inclusive nas políticas de restruturação urbanistica. Em resultado de catástrofes naturais (como no Terramoto de 1755) ou de determinações dirigistas (como no Estado Novo), os esventramentos urbanos mudaram, em diversas frentes, a face das principais cidades portuguesas.

A reconstrução de Lisboa, encetada pelos engenheiros-militares pombalinos, para além de traçar uma nova grelha de urbanização na Baixa da cidade, realinhou quarteirões resistentes ao terramoto, incorporando-os na nova "linguagem" iluminista. O Chiado é um exemplo dessa acção integradora, constituindo um tecido de fronteira e articulação com o velho Bairro Alto, algo que foi compreendido e reutilizado por Álvaro Siza Vieira no seu Plano de Reconstrução, após o incêndio de 1985. Ao propor uma sequência de pátios e passagens pelo interior dos quarteirões remanescentes, Siza Vieira transforma o esventramento urbano, aberto pelo fatídico sinistro, numa oportunidade de conectar física e funcionalmente este tecido com a Lisboa contemporânea.
Noutra escala, e no final do século XIX, Ressano Garcia rompe o bairro envolvente ao Passeio Público pombalino para rasgar a nova Avenida da Liberdade. No entanto, não descura a articulação desse novo e majestoso alinhamento com a escala dos bairros adjacentes - a Glória, o Príncipe Real e Santa Marta. É nesse diálogo com os tecidos preexistentes que o esventramento ganha sentido e se torna hoje numa parte indissociável da cidade. 0 mesmo se poderá dizer das avenidas novas abertas sobre terrenos e tecidos urbanos anteriores, como nos casos da Av. Sá da Bandeira em Coimbra ou na Av. dos Aliados do Porto.

Pelo contrário, o esventramento da Alta de Coimbra, em meados do século $X X$, rompe claramente a relação ancestral entre os colégios renascentistas e o casario medieval da Almedina. Na sua visão autista, a nova Alta Universitária sonhada pelo Estado Novo, ficará condenada a uma existência introvertida e esvaziada de uma verdadeira plurifuncionalidade urbana, ainda hoje visível. 
A natural mudança de

mentalidades em relação

ao património arquitectónico

e urbanístico da Baixinha,

altera radicalmente o sentido

do atravessamento proposto

décadas antes

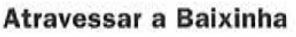

Para a Baixinha de Coimbra a política urbanística do Estado Novo traçou a desejada ligação entre o fundo da Sá da Bandeira (a avenida oitocentista nunca rematada) e a beira-rio.

A Avenida de Santa Cruz, desenhada por De Groer no seu Plano de Urbanização de 1940, resultava de um esventramento dos quarteirões da chamada Judiaria Nova, aproveitando o alinhamento da antiga runa de água proveniente do Vale de Santa Cruz. Desse traçado executaram-se apenas as demolições do denominado quarteirão do bota-abaixo, adjacente à Av. Fernão de Magalhães, permanecendo, no entanto, intacto o tecido próximo da R. da Sofia. A história mais recente é conhecida e serve de condicionante a este estudo.
Na década de 90, o Plano Director Municipal, através de uma proposta de Fernando Távora, retoma a problemática do atravessamento da Baixinha, agora tendo como pretexto infraestruturador o traçado do novo Metro Ligeiro de Coimbra.

A natural mudança das mentalidades em relação ao património arquitectónico e urbanístico da Baixinha, altera radicalmente o sentido do atravessamento proposto décadas antes, confinando-o agora ao interior de alguns quarteirões da Judiaria Nova uma vez que aceita a importância do tecido urbano e da escala dos arruamentos preexistentes (nos quais a R. Direita assume especial relevo). Assim, os constrangimentos técnicos e funcionais no traçado do Metro Ligeiro, propostos por diversos estudos de mobilidade para Coimbra, induzem a necessidade de demolir cirurgicamente algumas frentes e espaços interiores de, pelo menos, dois desses quarteirões, criando um canal de atravessamento até ao novo conjunto, entretanto construido, no bota-abaixo. 


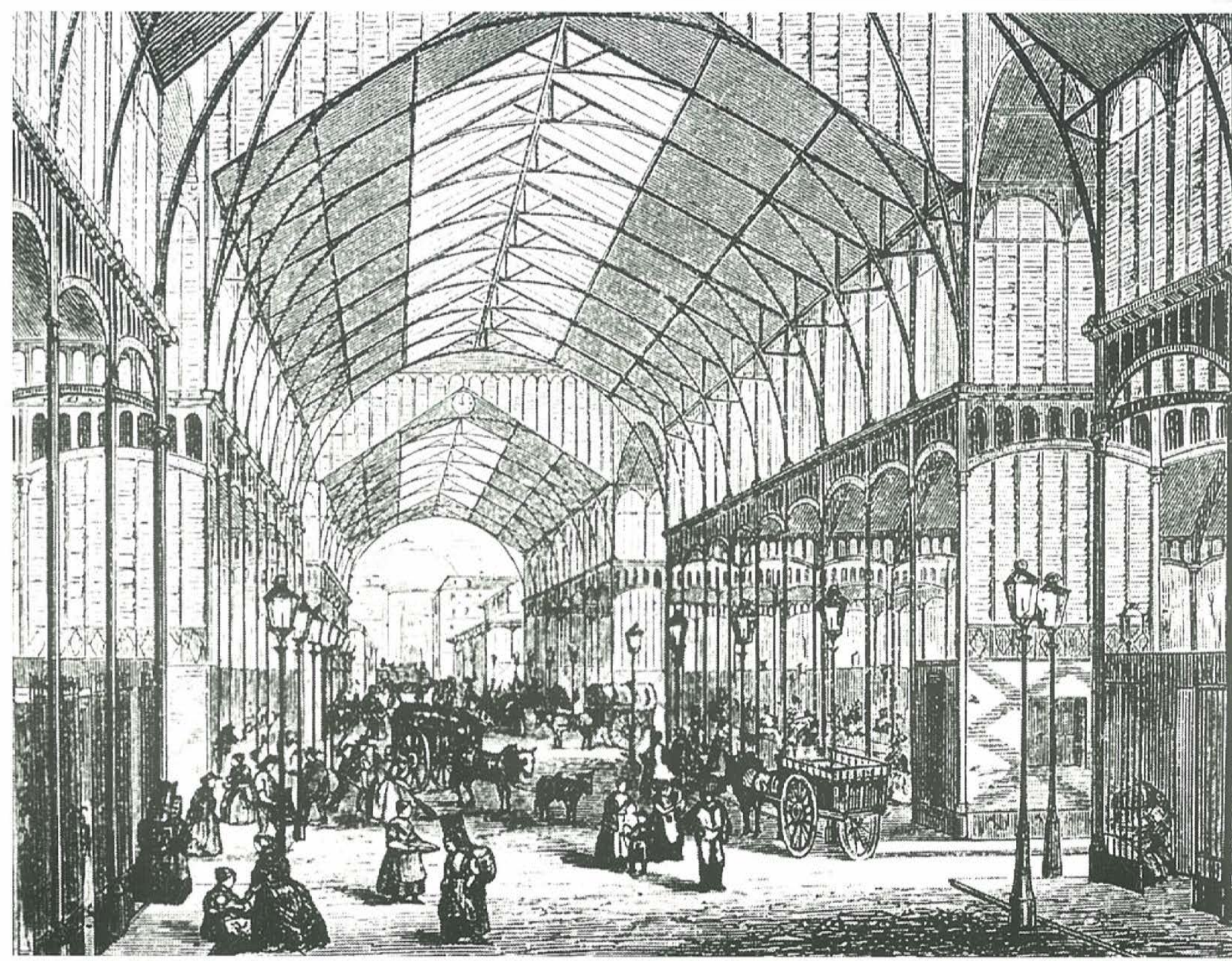

A determinação das várias hipóteses de traçado obriga ao conhecimento rigoroso da tipologia e morfologia do edificado existente, peças importantes que constam, de resto, do presente estudo. No entanto, e independentemente da solução a escolher, o atravessamento urbano da Baixinha deve ser visto como uma chance, sem precedentes, de ligar o ponto fulcral de articulação da Coimbra renascentista (R. da Sofia) com a Coimbra oitocentista (Av. Sá da Bandeira) à frente ribeirinha, cumprindo um desejo antigo da cidade. Esse atravessamento urbano permitirá redescobrir a cidade "invisivel" que conforma o interior da Judiaria Nova, potenciando o seu papel estratégico na cidade. No mesmo sentido, a localização de uma estação de Metro no interior do conjunto, servirá como factor de dinamização plurifuncional do seu tecido socio-económico "adormecido".
As soluções de inserção mais equilibradas serão aquelas que encontrem a justa adaptação da nova infraestrutura às arquitecturas propostas e preexistentes. Mas, tal como nas Passages de Paris, nas Arcades Iondrinas ou nos pátios do Chiado lisboeta, essa justeza deverá deixarnos perceber que ali se encontram e se articulam diferentes tempos da mesma cidade, incluindo o nosso próprio tempo. Esse será o sinal de que Coimbra soube fazer de um velho sacrifício uma nova oportunidade de regeneraçāo. 


\title{
PROGRAMA PRELIMINAR
}

\author{
MEMÓRIA DESCRITIVA E JUSTIFICATIVA
}

O Estudo Preliminar elaborado aponta duas hipóteses de intervenção nos quarteirões em causa (hipóteses A e B). Embora significativamente distintas, ambas assentam no princípio comum de que a intervenção deverá constituir um polo dinamizador da baixa da cidade, aproveitando a oportunidade para a criação de novas frentes urbanas e de um espaço público de qualidade que sirva de motor de transformação e requalificação do tecido urbano degradado, para o qual contribui significativamente a localização da paragem no interior do quarteirão junto à rua da Sofia, em detrimento da opção de localização na rua Olímpio Nicolau Fernandes, que se revela de difícil resolução.

Com base no estudo fornecido pelo Departamento de Engenharia Civil da F.C.T.U.C., não será possível manter os edifícios da Rua João Cabreira, devido ao seu estado de conservação e à constituição dos solos.

Prevê-se, assim, a sua reconstrução, mantendo as fachadas ao longo da rua em qualquer das hipóteses de intervenção.

\section{Programa Preliminar do atravessamento do}

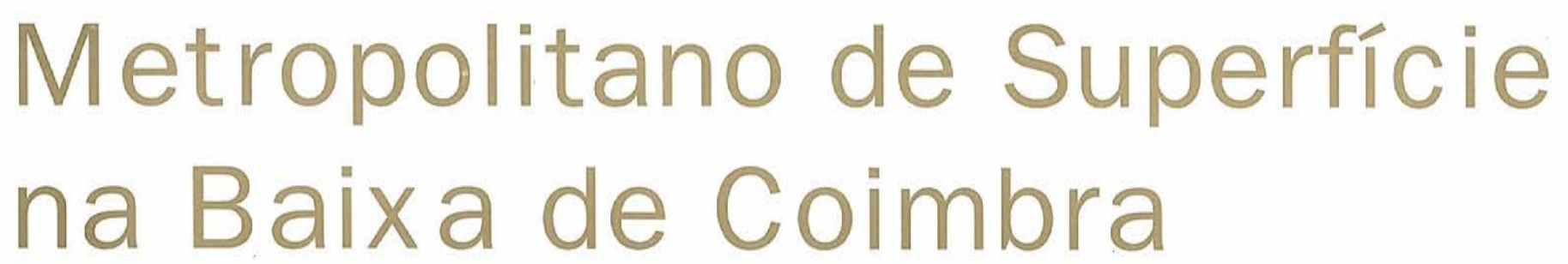




\section{Proposta A}

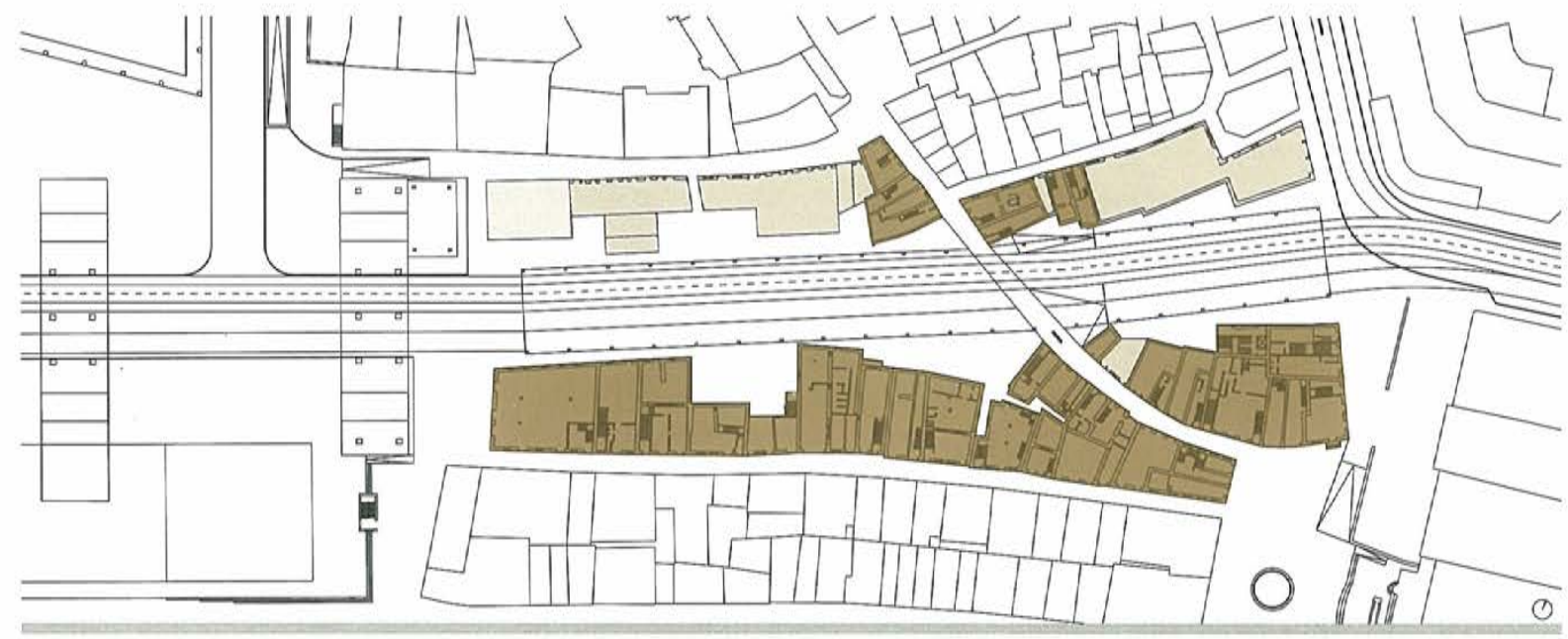

Planta de Contacto

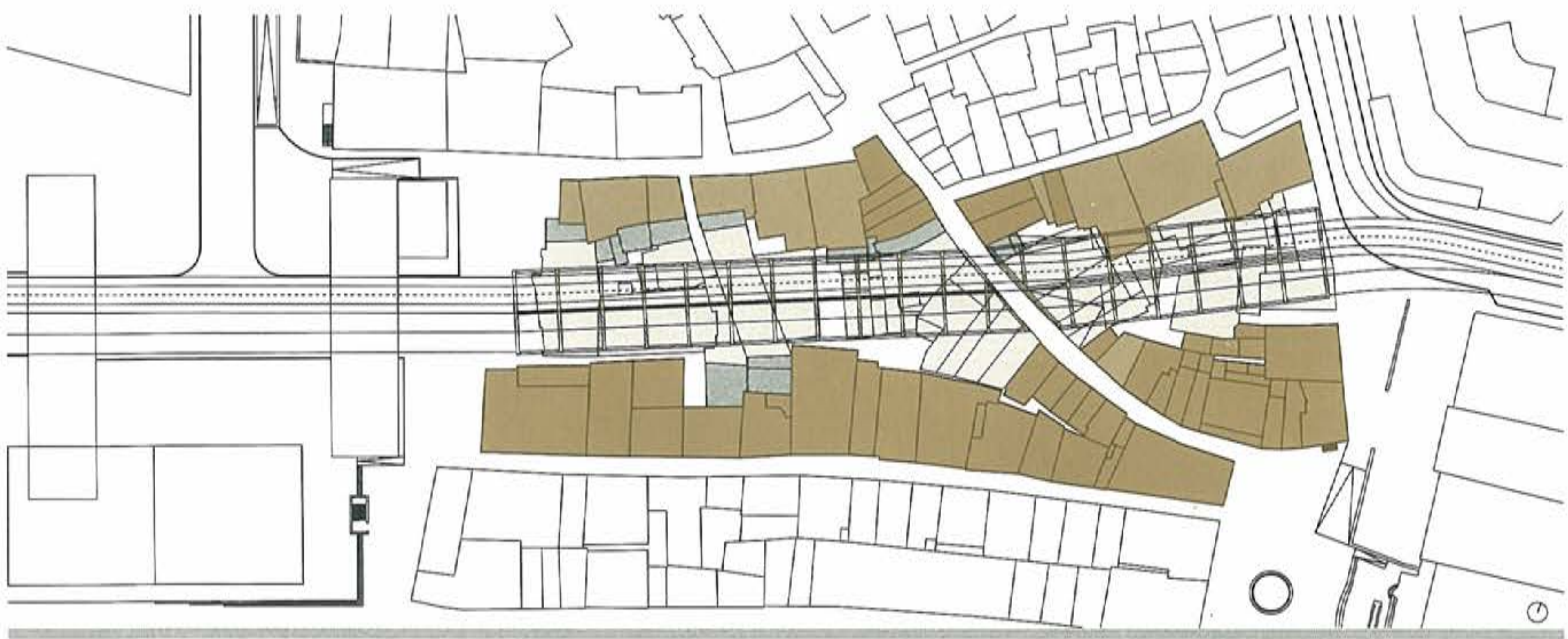

Edificio Existonte

A manter
Edificelo a Demolir Previsto no AP

$2348 \mathrm{~m} 2$

[área de implantaçio|
Edificlo a Demollt Não Previsto no AP

$295 \mathrm{~m} 2$

[área de implantaçąo]
Edifíclo a Ro-Constrult Mantendo Fachada Existente
Planta de Coberturas

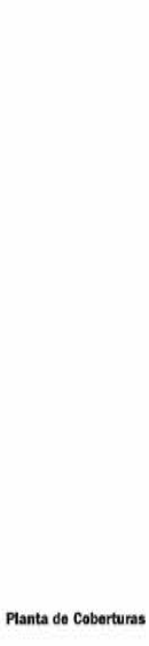


Esta solução aponta para a criação de uma estrutura com autonomia formal que assume o esventramento dos dois quarteirōes, percorrendo-os desde a Rua da Sofia até ao "Bota-a-Baixo". Referencia-se nas "passages" do século XIX, construídas em diversas cidades da Europa, como Milão, Paris ou Bruxelas, revendo-se o modelo para um clima distinto, numa linguagem contemporânea. O perfil da estrutura engloba duas linhas de metro e uma faixa rodoviária, cujo traçado mantém, tanto quanto possivel, as construções periféricas salvaguardando a malha urbana envolvente, a sua escala e carácter.
Será interrompida na Rua Direita por forma a minimizar o impacto da intervenção, respeitando os actuais limites que as construções existentes estabelecem. A estrutura, em perfis metálicos ou de madeira, deverá constituir um filtro com relativa transparência, criando um espaço exterior cober to que permite a ventilação e a passagem da luz solar, filtrada, materializando uma segunda fachada que permite a gradual requalificação das construções adjacentes, a começar desde logo pelos pisos térreos, que pela sua função genericamente comercial, adquirem a mais valia de uma segunda frente para o novo espaço público. A criação de percursos transversais pontuais (através do beco do Amorim e do $\mathrm{r} / \mathrm{c}$ de constru- ções renovadas) permitiră a ligação das ruas João Cabreira, da Moeda e da Loiça, contribuindo para a integração do novo espaço público na malha urbana da baixa.

Levanta-se a possibilidade de construção de um ou vários equipamentos dentro da própria galeria, ao nível do piso elevado, os quais poderão constituir uma mais valia para a intervenção. Como referido acima, a opção de localizar a paragem do metro no interior do quarteirão, junto à Rua da Sofia, contri buirá decisivamente para a apropriação do novo espaço público, induzindo a utilização da galeria e garantindo a centralidade do acesso ao novo meio de transporte.

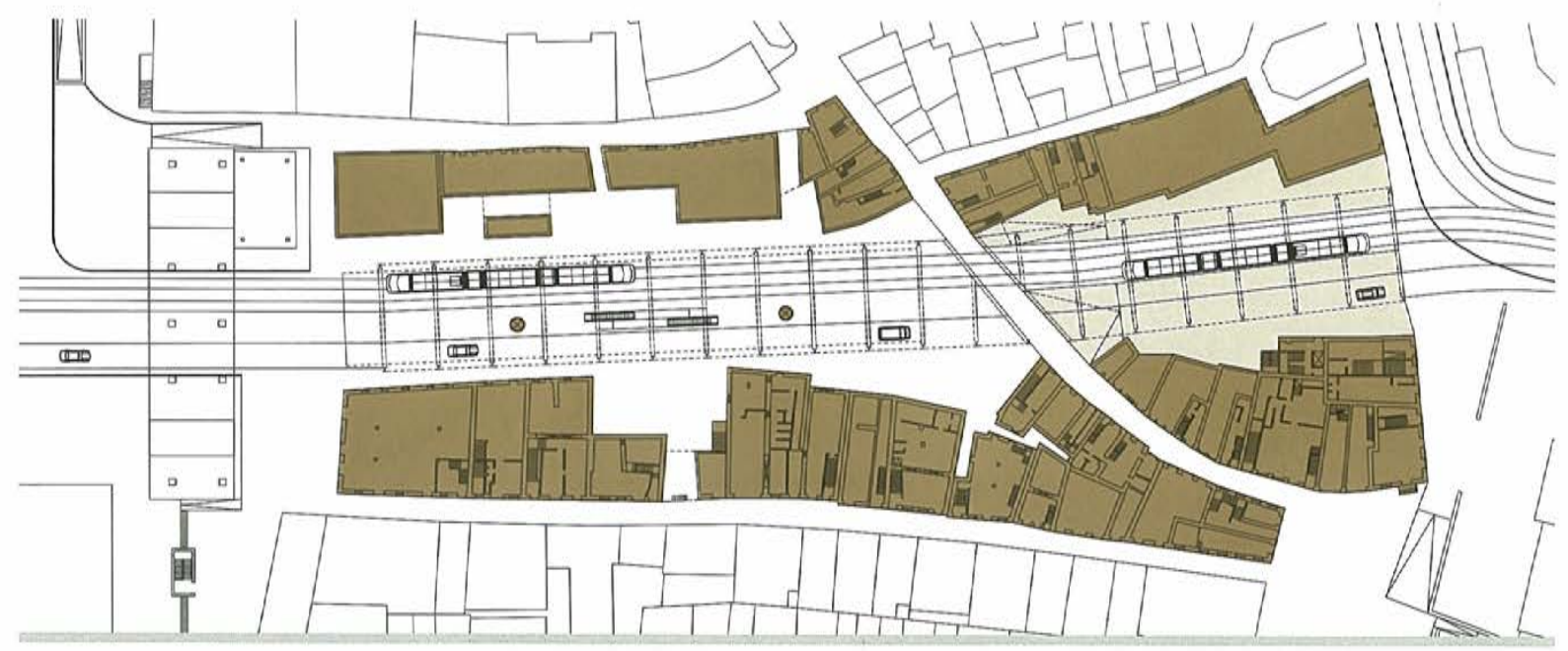


Na rua da Sofia estão sujeitos a demolição o edifício da Misericórdia e da farmácia "Luciano e Matos". 0 edifício da padaria "Palmeira" e do restaurante “A Democrática", na rua Nova, serão reconstruídos mantendo as fachadas frontais e recuando a volumetria no interior do quarteirão. 0 corpo poente do edifício camarário, no interior do quarteirão, será igualmente sujeito a demolição.

Propõe-se ainda a construção de um novo edifício no extremo poente da rua Joāo Cabreira, de forma a resolver a transição do espaço público criado para a área do "Bota-a-Baixo".
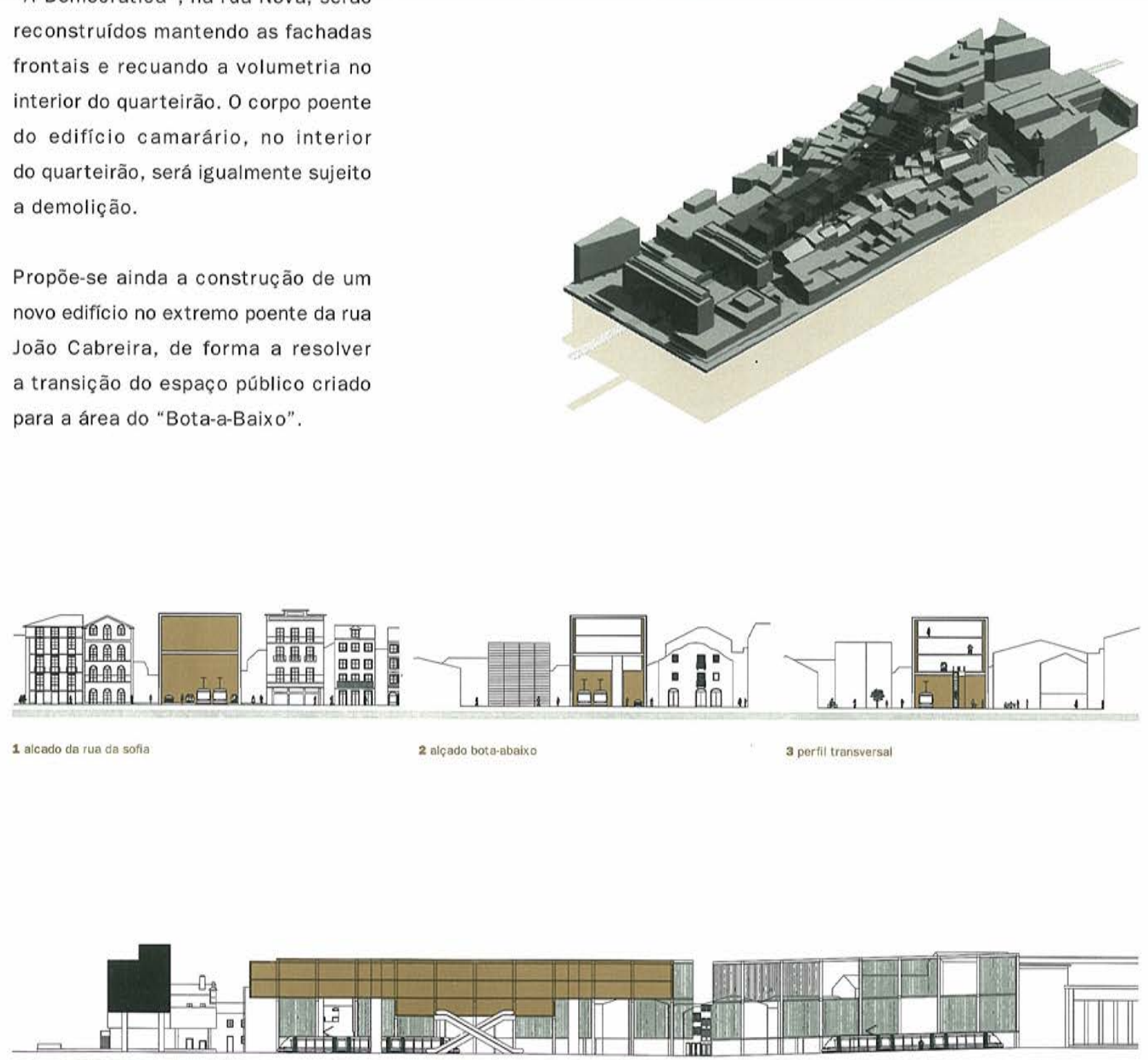

4 perfil longitudinal 


\section{Proposta B}

A estratégia desta solução assenta na criação de "edifícios-ponte", fechando os quarteirões ao nivel dos pisos de cota superior e mantendo a acessibilidade ao seu interior ao nível do peão. Minimiza-se a intervenção quer na rua da Sofia, quer na rua Direita.
O primeiro edificio propõe-se como substituição do edifício da farmácia “Luciano e Matos, mantendo o edifício da Misericórdia, e sendo o acesso feito pelo interior do edificio da padaria "Palmeira", cuja reconstrução se torna necessária devido ao traçado do metropolitano.
Da mesma forma que na hipótese anterior, a reconstrução deste edifício e dos que Ihe estão adjacentes ("A Democrática"), prevê o recuo da volumetria no interior do quarteirão, mantendo as fachadas frontais. A paragem do metro localiza-se neste primeiro quarteirão,

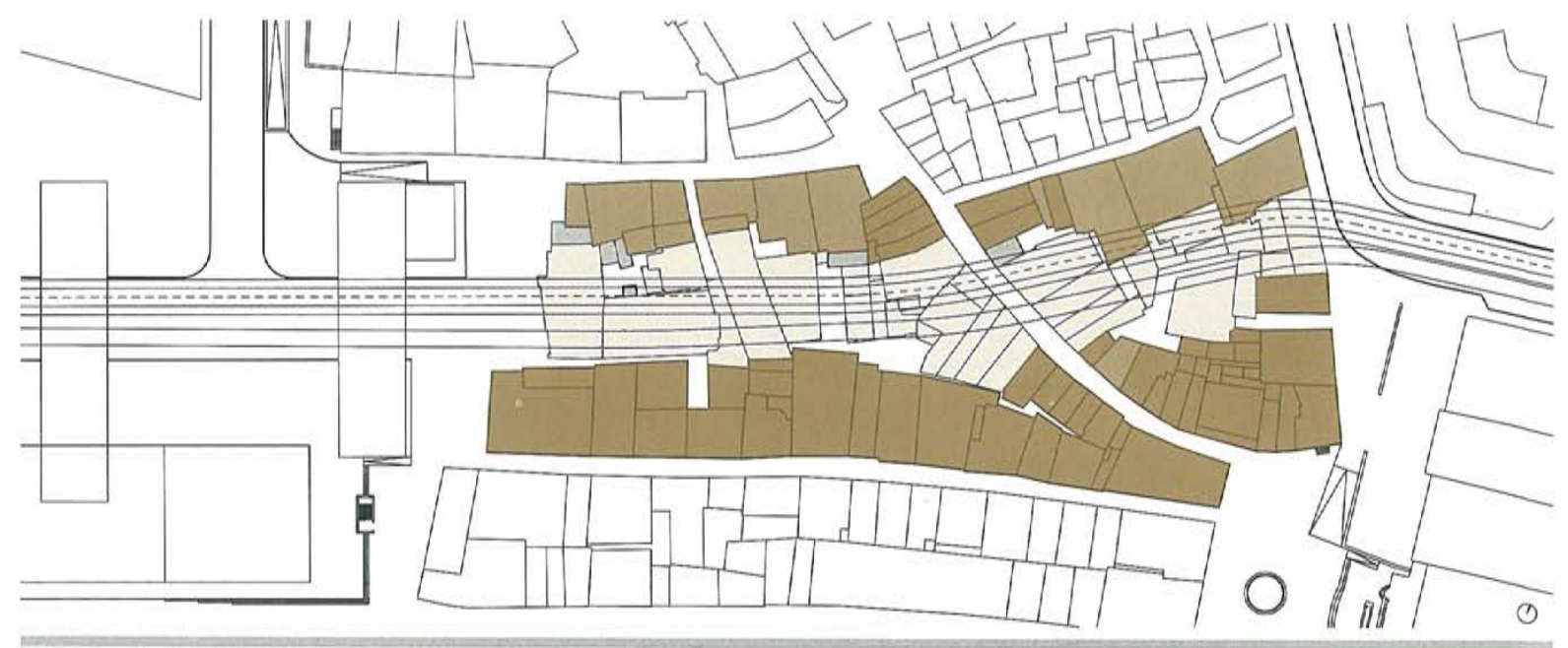




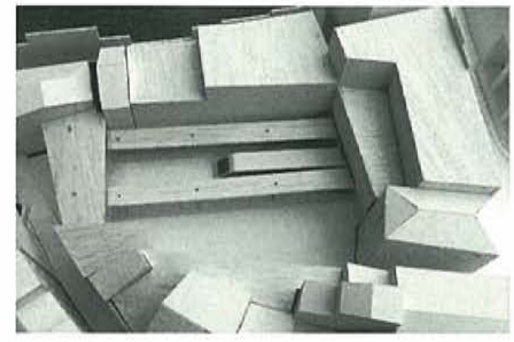

abrindo-se subtilmente para a rua Direita, cujo limite se definirá com uma estrutura leve a criar, relacionada com as coberturas da paragem. $\mathrm{Na}$ frente convexa da rua Direita, o segundo "edifício-ponte" mantém o alinhamento das construções existentes, permitindo $o$ acesso ao segundo quarteirão ao nível da rua.

Os atravessamentos, existentes ou a criar, possibilitando a passagem entre as ruas João Cabreira, da Moeda e da Loiça, continuam a assegurar, nesta hipótese, a permeabilidade deste espaço público

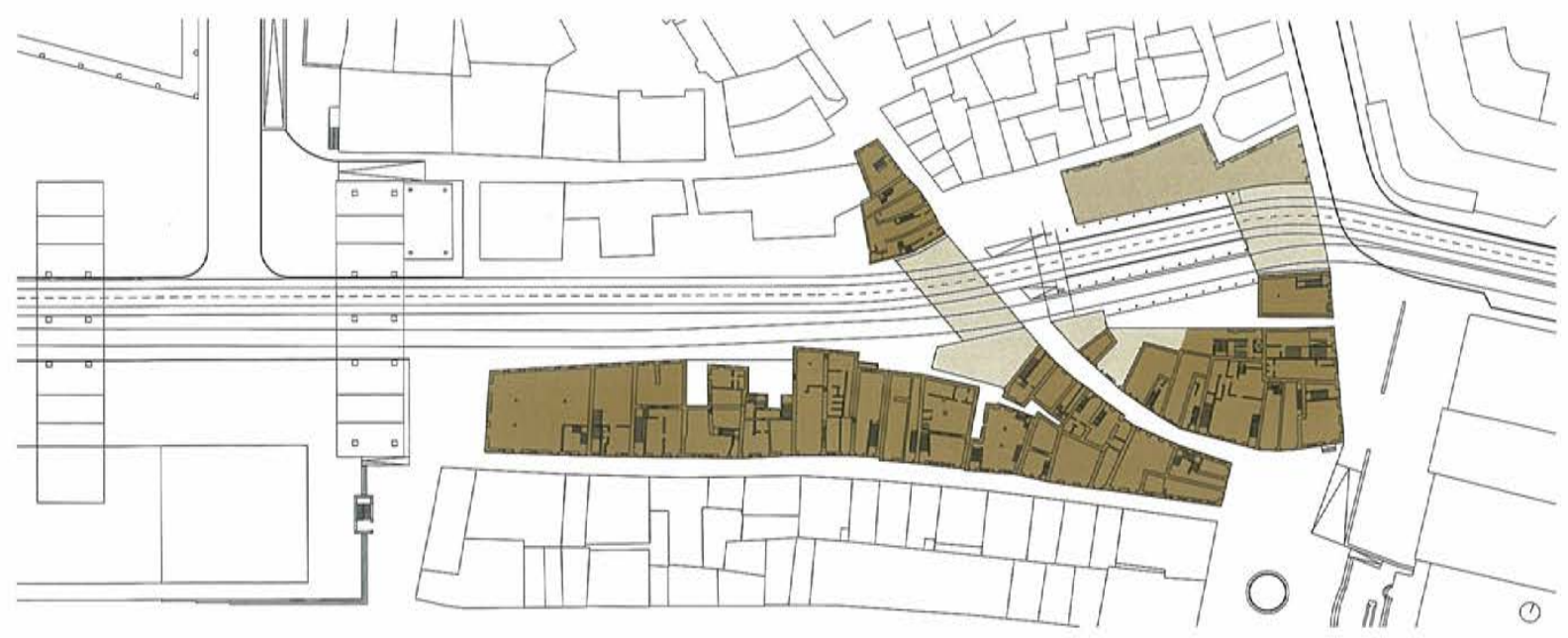

Edificio Existente A manter
Edificio a Construir

$250 \mathrm{~m} 2$ |área brutal
Edificio a Re-Construir Mantendo Fachada Existente 
Vista da Rua da Sofia

que se quer parte integrante e integradora da malha urbana existente.

Ao contrário da hipótese $\mathrm{A}$, a qualificação dos edificios existentes e das suas fachadas tardoz revela-se mais premente nesta solução, uma vez que a qualidade espacial da área de atravessamento dependerá dos edifícios que a conformam, obrigando, assim, a uma intervenção mais profunda e menos demorada.
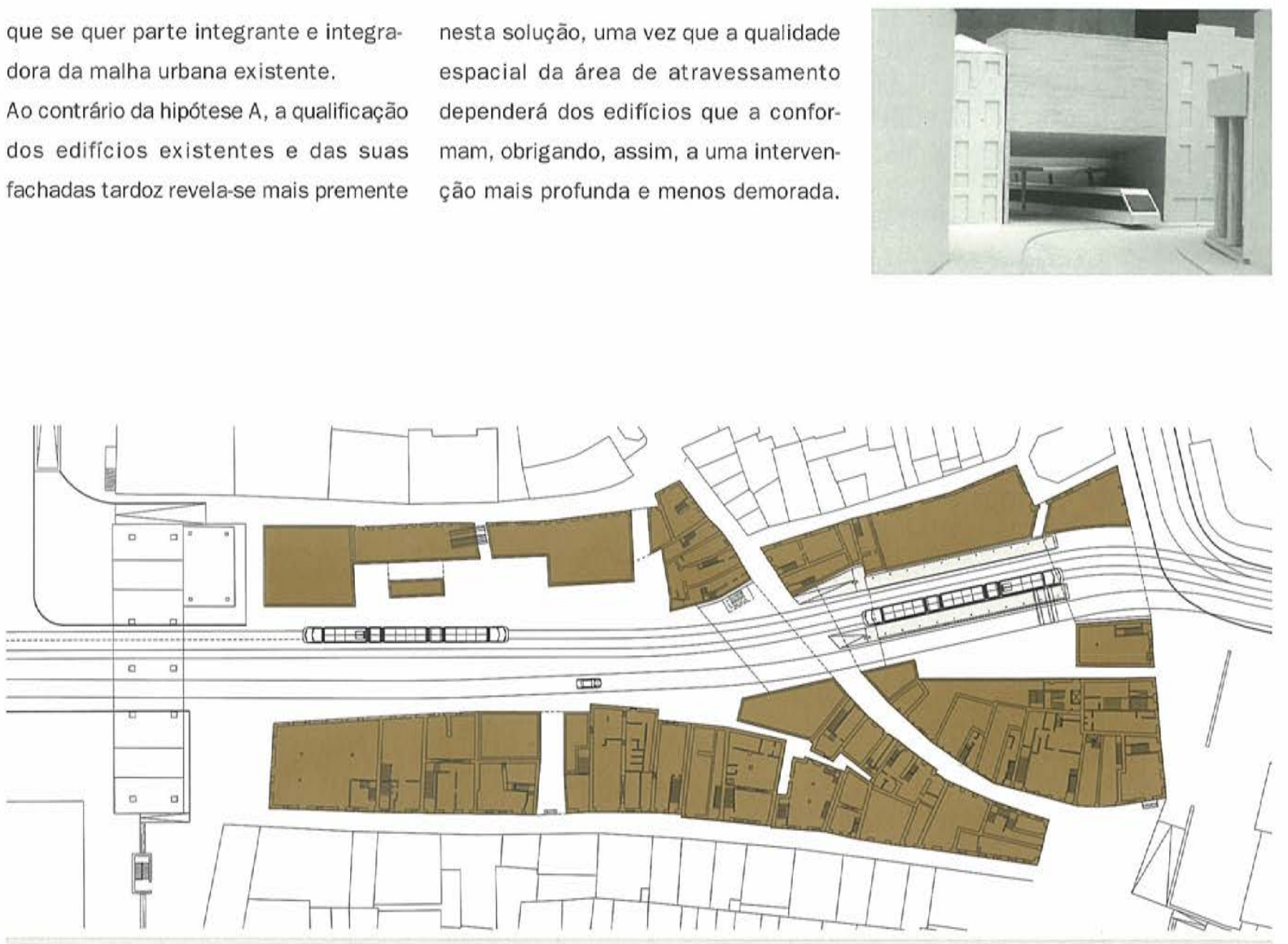

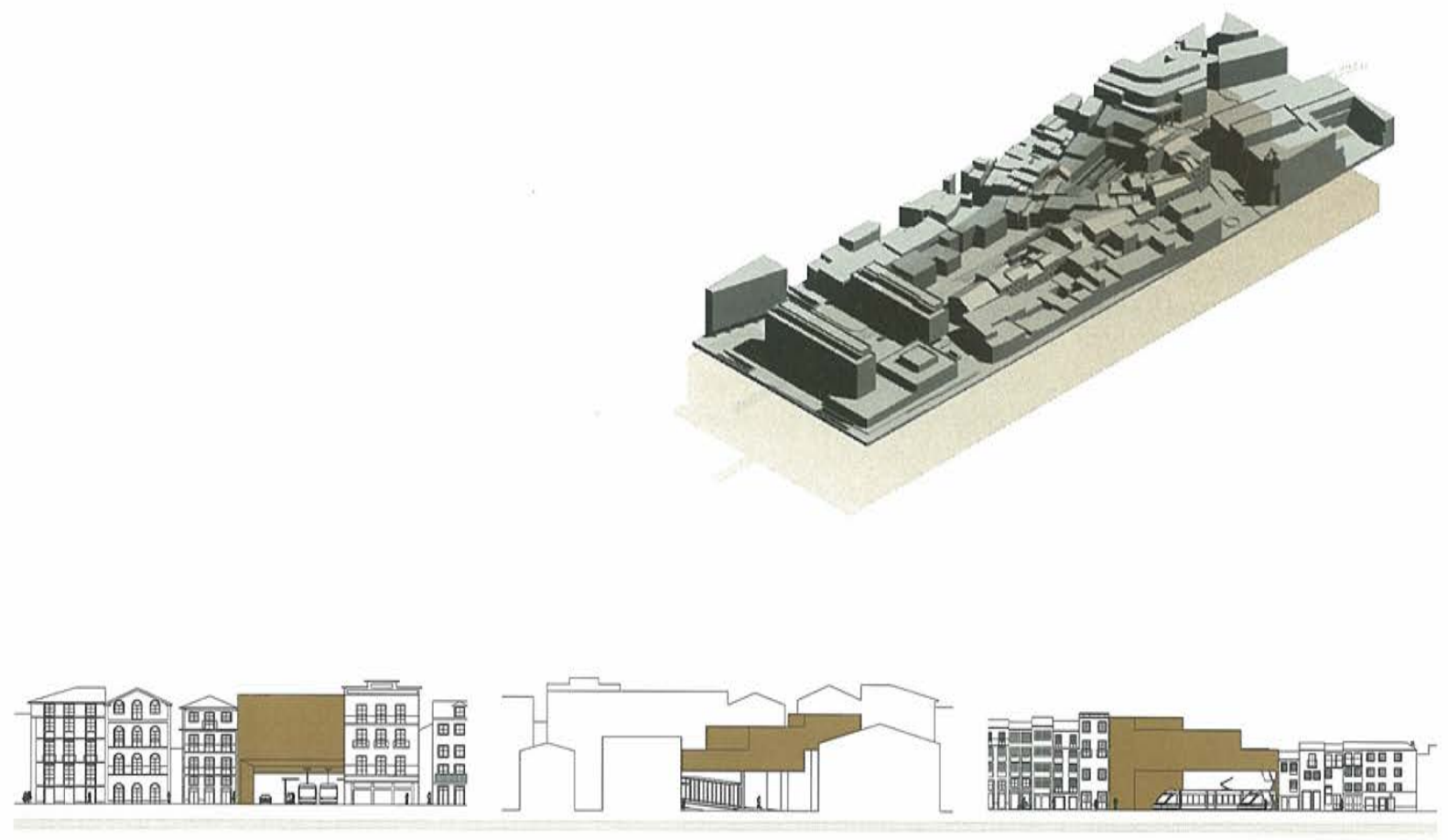

1 alcado da rua da sofia

2 perfil transversal

3 perfil Rua da Sofia

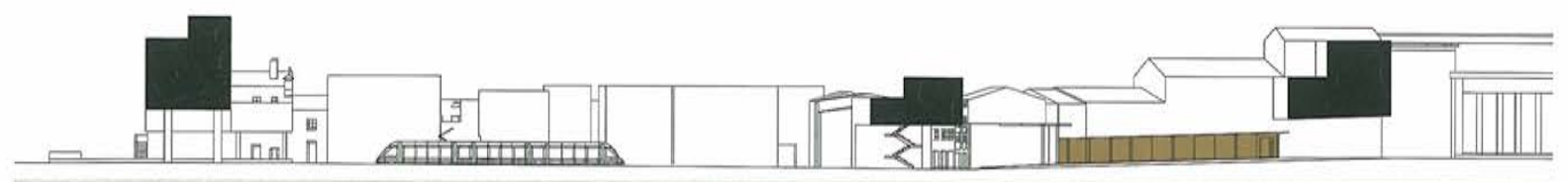

4 perfil longitudinal $\begin{array}{ll}\text { FICHA TÉCNICA } & \text { Trabalho eiaborado pelo } \\ \text { Centro de Estudos } \\ \text { de Arquitectura }\end{array}$
Coordenador Prof. Arq. Gonçalo Byrne

Arq. Nuno Grande

Arq. Ruí Labo
Arq. Armando Rabaça
Colaboradores

André Mota

Claudia Fidalgo

Luis Filipe Roch

Paulo Pedro
Cearq-FCTUC

10 de Feveroiro de 2003

METRO (2E.DT) 